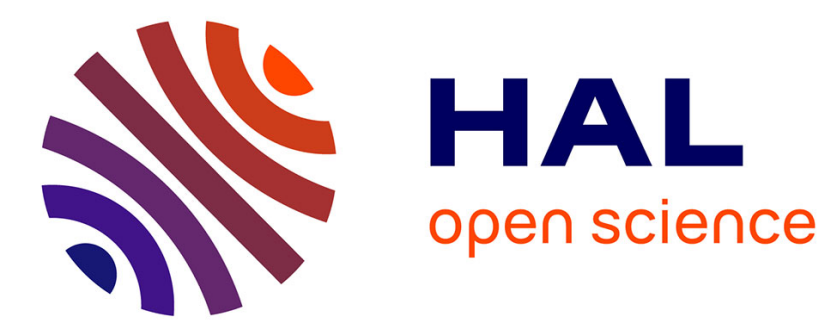

\title{
Public Research in Regional Networks of Innovators: A Comparative Study of Four East-German Regions
}

\author{
Holger Graf, Tobias Henning
}

\section{To cite this version:}

Holger Graf, Tobias Henning. Public Research in Regional Networks of Innovators: A Comparative Study of Four East-German Regions. Regional Studies, 2009, 43 (10), pp.1349-1368. 10.1080/00343400802251460 . hal-00538019

\section{HAL Id: hal-00538019 \\ https://hal.science/hal-00538019}

Submitted on 20 Nov 2010

HAL is a multi-disciplinary open access archive for the deposit and dissemination of scientific research documents, whether they are published or not. The documents may come from teaching and research institutions in France or abroad, or from public or private research centers.
L'archive ouverte pluridisciplinaire HAL, est destinée au dépôt et à la diffusion de documents scientifiques de niveau recherche, publiés ou non, émanant des établissements d'enseignement et de recherche français ou étrangers, des laboratoires publics ou privés. 


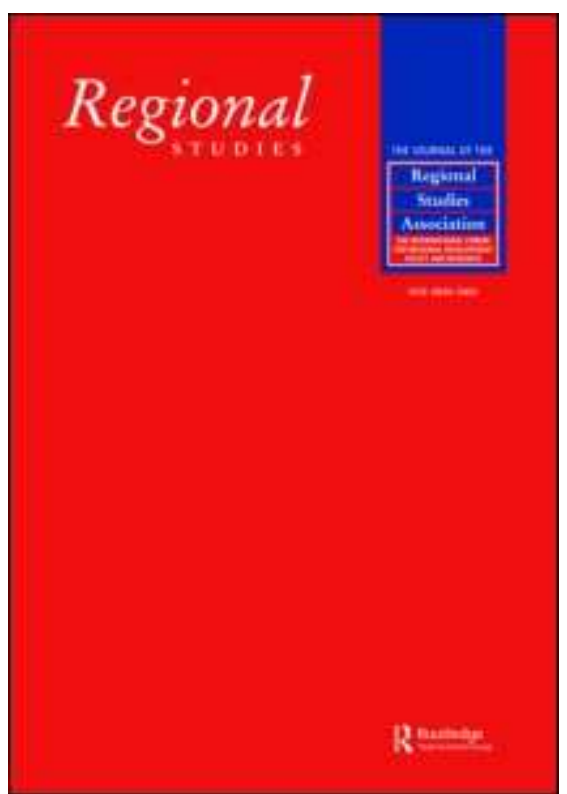

\section{Public Research in Regional Networks of Innovators: A Comparative Study of Four East-German Regions}

\begin{tabular}{|r|l|}
\hline Journal: & Regional Studies \\
\hline Manuscript ID: & CRES-2006-0252.R2 \\
\hline Manuscript Type: & Main Section \\
\hline JEL codes: & $\begin{array}{l}\text { O31 - Innovation and Invention: Processes and Incentives }<\text { O3 - } \\
\text { Dechnological Change|Research and Development < O - Economic } \\
\text { Economic Activity: Growth, Development, and Changes }<\text { R1 - } \\
\text { General Regional Economics < R - Urban, Rural, and Regional } \\
\text { Economics }\end{array}$ \\
\hline Keywords: & $\begin{array}{l}\text { Innovator networks, Public research, R\&D cooperation, Scientist } \\
\text { mobility }\end{array}$ \\
\hline
\end{tabular}

\section{SCHOLARONE" Manuscripts}




\title{
Public Research in Regional Networks of Innovators: A Comparative Study of Four East- German Regions
}

\author{
Holger Graf \\ Friedrich Schiller University of Jena \\ School of Economics and Business Ädministration \\ Carl-Zeiss-Str. 3 \\ 07743 Jena, Germany \\ holger.graf@uni-jena.de \\ and \\ Tobias Henning \\ Bibliographisches Institut $\mathrm{GmbH}$ \\ Querstraße 18 \\ 04103 Leipzig, Germany, \\ tobias.henning@bifab.de \\ First received: October 2006 \\ Accepted: March 2008
}

Deleted: December 04, 2007

Formatted: German Germany

Formatted: German Germany

Formatted: German Germany

Formatted: English U.K.

Formatted: English U.K.

\begin{abstract}
Universities and public research organizations are said to be integrative and essential elements of a functioning innovation system. We analyze four East German regional networks of innovators and investigate the characteristic role of public research within these networks by applying methods of social network analysis using patent data. Our results show that universities and non-university institutions of public research are key actors in all regional networks. Differences between regional innovative performance seem to be related to differences in the structural properties of the networks.
\end{abstract}

Keywords: Innovator networks; Public research; R\&D cooperation; Scientist mobility

JEL Classification: R11; O31; Z13

La recherche publique sur les réseaux régionaux d'innovateurs:

une étude comparative de quatre régions situées en Allemagne de l'Est.

\section{Graf \& Henning}

On dit que les universités et les établissements de recherche publics constituent des parties intégrantes et essentielles d'un système d'innovation opérationnel. Ici, on analyse quatre réseaux régionaux d'innovateurs en Allemagne de l'Est et à examiner le rôle type de la recherche publique au sein de ces réseaux en employant des méthodes 
qui cherche à analyser les réseaux sociaux à partir des données sur les brevets. Les résultats laissent voir que les universités et les établissements de recherche publique en dehors des universités sont des éléments clé de tout réseau régional. Il semble que les différences de la performance régionale d'innovation se rapportent aux différences des propriétés structurelles des réseaux.

Réseaux d'innovateurs / Recherche publique / Coopération en R et D /

Mobilité des scientifiques

Classement JEL: R11; O31; Z13

Öffentliche Forschung in regionalen Netzwerken von Innovatoren: eine vergleichende Studie von vier ostdeutschen Regionen

Holger Graf and Tobias Henning

Abstract

Universitäten und öffentliche Forschungseinrichtungen gelten als integrative und wesentliche Bestandteile eines funktionierenden Innovationssystems. Wir analysieren vier ostdeutsche regionale Netzwerke von Innovatoren und untersuchen die charakteristische Rolle der öffentlichen Forschung innerhalb dieser Netzwerke, indem wir unter Verwendung von Patentdaten Methoden der Sozialnetzwerkanalyse anwenden. Unsere Ergebnisse zeigen, dass Universitäten und nichtuniversitäre Einrichtungen der öffentlichen Forschung in sämtlichen regionalen Netzwerken zentrale Akteure darstellen. Die Unterschiede zwischen der regionalen innovativen Leistung scheinen mit Unterschieden hinsichtlich der strukturellen Eigenschaften der Netzwerke zusammenzuhängen.

\section{Keywords:}

Netzwerke von Innovatoren

Öffentliche Forschung

Zusammenarbeit bei F\&E

Mobilität von Wissenschaftlern

JEL Classification: R11; O31; Z13

Investigación pública en las redes regionales de innovadores: un estudio comparativo de cuatro regiones de Alemania del Este

Holger Graf and Tobias Henning

\section{$\underline{\text { Abstract }}$}

Las universidades y las organizaciones de investigación públicas se consideran elementos integradores e indispensables de un sistema de innovación en funcionamiento. Analizamos cuatro redes regionales de innovadores de Alemania del Este e investigamos el rol característico de la investigación pública en estas redes con ayuda de métodos analíticos de redes sociales 
usando datos de patentes. Nuestros resultados indican que las instituciones universitarias y no universitarias de investigación pública son los participantes clave de todas las redes regionales. Las diferencias entre el desempeño innovador regional parecen estar relacionadas con las diferencias en las propiedades estructurales de las redes.

\section{Keywords:}

Redes de innovadores

Investigación pública

Cooperación de I+D

Movilidad científica

JEL Classification: R11; O31; Z13

\section{Introduction}

Innovation is an interactive and highly systemic process involving many actors from different parts of the economy (e.g. LUNDVALL, 1992; NELSON, 1993; EDQUIST, 1997). The transfer of knowledge between networked actors is central to this systemic approach to innovation and geography becomes relevant as knowledge flows have shown to be regionally bounded (JAFFE et al., 1993). The main argument is that new knowledge has tacit components which can only be transferred via personal relationships. Geographical proximity facilitates these face-to-face contacts, even though it is certainly not a sufficient condition (BRESCHI and LISSONI, 2003; BOSCHMA, 2005). The regional innovation system approach is a concept building on these ideas, emphasizing the fact that regional interactions are embedded within an environment of specific institutions guiding the innovation process (COOKE, 1998). While there are many studies on regional innovation systems, only few take into account the structure of actor to actor relationships within these systems. In the present study, we focus on these relations between innovative actors (firms, public research, and individuals) and the resulting structure of the innovation network and not on the broader 
institutional environment (e.g. norms or culture) or the role of political actors. As such, we investigate only a part of the regional innovation system, but one that appears to be vital for the functioning of such a system.

We analyze regional networks of patenting innovators in four East German regions with special attention to the role of public research within these networks. The work is exploratory in nature and is led by the general assumption that a region's innovative output is influenced by the quality and intensity of regional innovative networking. Our research is motivated by two questions: i) what are the structural differences between the regional innovator networks and ii) what is the role of public research in such networks.

Following CANTNER and GRAF (2006), we use relational patent data to construct these networks. More precisely, we link patent innovators both by joint application and the mobility of inventors, and we interpret these links as knowledge flows. According to a distinction put forth by BRESCHI and LISSONI (2004), we analyze relationships based on co-patenting as well as on co-invention. However, patents are also used in the traditional way as an indicator of innovative output both to weight the network actors and to assess the innovative performance of the regions as a whole.

Among the network actors, we are explicitly interested in public research organizations, i.e., universities and non-university publicly funded research institutes, since geographical proximity seems to be especially important for their interactions with industry (FRITSCH, 2001). One function public research is usually expected to serve within local innovation systems is the provision of innovative input to the region by i) generating and accumulating basic scientific knowledge, ii) collecting knowledge external to the region and integrating it into the regional knowledge stock, and iii) 
educating a highly skilled workforce to keep the region's private economy capable of performing high-level industrial R\&D (FRITSCH and SCHWIRTEN, 1999). Furthermore, since public actors have different motives and incentives than private actors, they may well play a specific and presumably essential role within the process of collective invention and shape the regional networks.

We proceed as follows: in section 2 , we introduce the four sample regions and compare their innovative performance by means of employment and patent output data. The methodological approach of social network analysis is introduced in section 3, while in section 4 , we discuss the structural properties of the regional innovator networks in a comparative way. The distinctive role of public research organizations in these networks is analyzed in section 5, followed by our conclusions in section 6 .

\section{The Regions: Dresden, Jena, Halle, and Rostock}

\subsection{Selection of Regions}

The eastern part of Germany provides an interesting case for regional economics. Regions within the former GDR started with more or less the same troublesome starting conditions after German reunification. Organizational structures have been distorted as the combines have been broken apart and the socialist system of planned innovation was replaced by entrepreneurial innovation in the competitive market economy. But still, historical economic patterns have their influence, and even new establishments are often shaped by old industrial heritage. For the present study, we leave out the most turbulent time right after 1990 and investigate the years from 1995 until 2001. We decided to analyze the four East German regions of Dresden, Jena, Halle, and Rostock, as they appear sufficiently similar to be comparable and sufficiently different to provide interesting findings. 
With the exception of Rostock, all regions are of comparable size, ranging from 800.000 to one million inhabitants (table 1). Each region contains a research university and a number of public research organizations such as institutes of the FraunhoferGesellschaft, the Leibniz Association, and the Max Planck Society. All regions have a considerable tradition in manufacturing industries: electronics and mechanical engineering in Dresden, optics and precision mechanics in Jena, chemicals in Halle, shipbuilding and mechanical engineering in Rostock. Two types of regions can be distinguished, as Jena and Dresden, on the one hand, are often labelled as East-German boom regions that have successfully managed the economic transformation after German reunification, whereas Rostock and Halle, on the other hand, are said to lag behind.

The geographical boundaries of the regions are defined as German planning regions ("Raumordnungsregionen"). Designed to represent socio-economic entities, they normally comprise several NUTS3 level districts, namely a core city and its surrounding area. We consider planning regions to be more suitable than districts. In the first place, the core city districts seem to be too small because local innovation systems may well include some R\&D capacities located beyond the boundaries of the core city. The second reason is methodological: since patents are assigned to regions in accordance with the inventors' residence, this larger regional unit allows us to account for commuting inventors who work in the city but live in the surrounding areas.

\subsection{Innovative Potential and Patent Output}

As a starting point and to provide a reference framework for the following investigation of the networks of innovators, we present some basic informations on the regions and their patenting activities in table 1 . 
The regional differences are small with respect to the share of private sector employees in total population (25\% up to $28 \%$ ) as well as to the average establishment ${ }^{1}$ size (10.0 up to 11.5 employees per establishment). But we observe striking differences regarding the share of private sector natural scientists and engineers. Halle displays only about $75 \%$ of the Dresden value, Rostock and Jena only about $62 \%$. The absolute number of natural scientists and engineers employed is by far highest in Dresden.

Why do we stress this point? Most patents refer to technical solutions applicable in the fields of natural science and engineering. Performing research with a patentable output normally requires skilled experts in these fields. Yet the number of natural scientists and engineers employed is a reasonable proxy for the regional pool of potential inventors. In fact, the number of private sector natural scientists and engineers turns out to be highly significant in explaining regional patent output (FRITSCH and SLAVTCHEV, 2005).

In a similar way, the scientific staff at universities in natural sciences and engineering disciplines may be interpreted as the pool of potential academic inventors. Again, Dresden shows the most distinctive orientation towards fields most likely to generate academic patents. In absolute figures, the number of natural scientists and engineers in Dresden employed by the university is twice as high as that of Halle, which ranks second. In all regions, the pool of potential inventors at universities is of significant size compared to the respective private sector pool (between 16\% in Halle and $23 \%$ in Rostock).

(TABLE 1 ABOUT HERE)

Relating patent numbers to the numbers of potential inventors results in patent efficiency measures, as reported in the last section of table 1. A substantial gap between 
the leading regions of Dresden and Jena, on the one side, and the lagging regions of Halle and Rostock, on the other, can be observed. The three different measures of patent efficiency can be read as a step-by-step approximation to the relevant input pool as a reference for patent output. Patent intensity, defined as patents per capita, is highest in Dresden, followed by Jena, Halle, and Rostock. With an average yearly patent intensity of 45 patent applications per 100,000 inhabitants, Dresden is ranked somewhere in the middle of all German planning regions (GREIF and SCHMIEDL, 2002). The order between the regions is left unchanged, but with Jena closing the gap with Dresden and Halle lagging behind, if employees are used as a more appropriate measure of innovative potential. Finally, if we apply the number of natural scientists and engineers that we assume best represents the pool of potential patent inventors, Jena takes the lead from Dresden and the gap between the leading regions and Halle and Rostock widens.

This short inspection of the regions' innovative potential and performance reveals two main results: First, Dresden is the region with the largest potential to generate patents, both in terms of the share of natural scientists and engineers and in terms of their absolute number. Second, natural scientists and engineers in Jena exhibit the highest patenting productivity, though Jena's pool of potential inventors relative to all employees is not larger than in Rostock and is still smaller than in Halle in absolute figures.

There are two possible explanations for these differences in patent efficiency: First, it may be due to differences in the sectoral structure, and second, it could be a result of differences in the organization of the innovation process. While both factors are obviously intertwined, the present study is an investigation of the latter though we have to keep the former in mind when interpreting our results. 
Sectoral structure

Patents are granted for technical solutions, occuring mainly in manufacturing industries and, with the exception of the rising importance of software patents, even less so in the service sector (MAIRESSE and MOHNEN, 2003). Within manufacturing, the propensity to patent inventions differs across industries for various reasons. Industries with a relatively low level of patenting activity may not be less innovative but prefer other means to appropriate the results of innovative activity, such as secrecy and lead time, or they innovate in an incremental way that is not compatible with the requirements of being granted a patent (PAVITT, 1985; ARUNDEL and KABLA, 1998; BROUWER and KLEINKNECHT, 1999).

Information about the sectoral distribution of employees reveals that, in Jena, 22.1\% of all employees work in the manufacturing sector, whereas in Dresden, the respective share is $18.7 \%$, in Halle $15.9 \%$ and in Rostock $13.1 \%$. This corresponds to the order of the four regions with respect to patent efficiency, as shown in table 1, supporting the above argument that regions in which manufacturing is more important will show a higher innovative efficiency in terms of patents per employee. Within manufacturing, we find metals and machinery to be among the top three employing industries in all regions, but the highly innovative industry electronics, instruments and optics is of major importance only in Dresden and Jena. Transportation equipment in Rostock and Dresden and the chemical industry in Halle and Jena are also large employers. The focus on electronics, instruments and optics in Dresden and Jena appears to be an important factor in explaining the differences in patents per employed natural scientists and engineers in the last row of table 1.

Organization of the innovation process 
Besides the influence of sectoral structure, regional differences in patenting efficiency may also occur because the regions are not equally successful in generating novelty from a given knowledge base. The theory of innovation systems suggests that relationships between the actors involved in innovative activity are of crucial importance as knowledge flows between the actors are a prerequisite for learning processes that lead to higher innovative output (LUNDVALL and JOHNSON, 1994; CAPELLO and FAGGIAN, 2005; MALMBERG and MASKELL, 2006). In the following section, we employ the methodology of social network analysis to construct networks of personal relationships between innovators which can be interpreted as channels of knowledge transfer. The characteristics of the networks as a whole, and the special role of public research organizations within them, will be presented and used to derive some possible explanations for the observed regional differences in innovative performance.

\section{Social Network Analysis and Patent Data}

Social network analysis is a methodology developed mainly by sociologists and researchers in social psychology. ${ }^{2}$ It is based on the assumption that relationships among interacting units matter and has proven to be an attractive tool for many other disciplines such as sociology, economics, marketing, or industrial engineering (WASSERMANN and FAUST, 1994, p. 4).

An empirical application of the network approach poses rather strong constraints on the underlying data. BURT (1983) even argues that a participation of less than $100 \%$ of the actors under observation would seriously affect network data. The argument is that if a single observation goes missing, (n-1) potential data points get lost. Accordingly, samples should only be taken on the level of relations, i.e. not all types of relations 
between the actors have to be analyzed, only the ones in the focus of the study (SCOTT, 2000). While the argument seems convincing at first sight, recent attempts to assess the stability of network measures depending on sampling rates show that errors are not that severe and social network analysis can provide valuable insights (COSTENBADER and VALENTE, 2003).

Due to these concerns and the difficulties with retrieving relational informations on a large number of actors through survey methods, we decided to use patent data as the basis of our attempt to map the regional networks of innovators. While patents also have their drawbacks, they have the advantage of being widely available and databases are complete in the sense that all actors that patent their innovations are covered. As already noted in section 2, the use of patents is certainly problematic since not all novelties are or can be patented and information about the quality of patents is difficult to retrieve. Since we are interested in the connections between actors in the process of innovation, the output in terms of patent quality is not of critical importance. The problem of different patenting propensities between industries is more critical. For regions that are specialized in industries with a low share of patented innovations, we will observe a smaller number of actors (those not patenting are not covered) and fewer linkages are documented. In our view, the insights that are obtained by accounting for specific linkages and the possibilites to analyze the resulting structures outweigh the drawbacks, but one should always be aware of the restrictions of the underlying database.

In light of these pros and cons, a growing number of studies use patent information to apply social network analysis in the field of economics and economic geography. Some authors link inventors directly by assuming relations between inventors who jointly worked on patents (BALCONI et al., 2004; FLEMING et al., 2004, 2006), while 
others link the applicants via common inventors (BRESCHI and LISSONI, 2003; SINGH, 2003, 2005; CANTNER and GRAF, 2006). We pursue the latter approach to map the regional networks of innovators and analyze patent applications at the German Patent Office which were disclosed between 1995 and 2001. The regional assignment of patents is based on the inventors' residence, i.e., we use all patent applications with at least one inventor residing in the respective region to construct the networks.

Our innovator networks are constructed in the following way. On each patent application, we find information about the applicant (for which we use the term innovator $^{3}$ ) and about the persons involved in the process of development of the patent (the inventors). We assume two innovators to be related if at least one inventor has developed a patent for both innovators. In other words, a relation is established between innovators A and B if we find an inventor on a patent applied for by $\mathrm{A}$ and on a patent applied for by B. There are two possibilities of how this might occur:

(1) The innovators jointly apply for a single patent. In this case, we assume a previous research cooperation and there are as many linkages between all coapplying innovators as there are inventors.

(2) The same inventor is named on two distinct patents applied for by different innovators. In this case, we assume mobility of the inventor between the innovators. $^{4}$

Both types of linkages are related to the notion of knowledge transfer through personal relationships (e.g. ALMEIDA and KOGUT, 1999). The main idea is that organizations, i.e. firms or research institutes interact via scientists who know each other either through working on joint projects (cooperation) or as they move from one organization to the other (mobility). Of course, mobility not only comprises the case of individuals 
changing jobs between existing organizations, but also spin-off processes in which new entities are formed by employees of incumbents. As these two cases, cooperation and mobility, differ in certain respects, we analyze them separately throughout the paper, but combine them to the network of personal relationships whenever it seems appropriate.

The sub-sample of public research includes the following organizations: research universities, technical colleges ("Fachhochschulen"), and non-university scientific institutes. The latter are in most cases members of one of the big German scientific institutions: the Max Planck Society, the Leibniz Association and the FraunhoferGesellschaft. In addition, we include a heterogeneous group of research organizations which are in many cases the successors of former socialist applied research institutes with close ties to industrial R\&D. To enter the group of public research, an organization has to rely at least partly on public funds to finance its regular budget.

Patent Data from Research Institutions: Critical Remarks

Until 2002, the German patent law allowed university professors to patent for their own account and not under the name of their university. In private firms as well as in nonuniversity public research organizations, the intellectual property rights connected to employees' inventions have always been in possession of the employer. As our data refer to a period previous to 2002 , the number of university patent applications is underestimated. In refining the database, we made an effort to compensate this bias by checking each individual innovator with a professor's degree as part of his name, if he or she was enrolled at one of the regional universities within the inspected period. If this was confirmed, the patent was added to the respective university's account.

The number of patent applications from public research is further underestimated 
because intellectual property rights are often traded against financial support. In university-industry cooperation projects, the private firm sponsors the research carried out in the university's lab, but claims the exclusive right to patent the invention in exchange. In consequence, there is not only an underestimation of public research patent activity, but even more importantly, a number of university-industry cooperations leading to patent output will not be identified as cooperative activity at all.

Another issue related to public research patenting is headquarter application: as with big private companies, universities frequently centralize their patenting activities. They appear as monolithic actors, but actually the inventions are made in the departments. Because of disciplinary boundaries, it cannot be assumed that there are steady knowledge flows between the departments. Therefore, if two actors both maintain patent relationships with the same university, this does not ensure that information is transferred between these two actors through the university.

\section{Regional Innovator Networks and the Role of Research Institutions}

\subsection{Graphical Analysis}

Before we investigate the network visualizations, some basic statistics regarding the data underlying the four regional networks are given in table 2. The first observation is that the regions differ strongly in the level of overall patent activity and network size. Dresden shows 3,269 applications during the 1995-2001 period or 467 applications per year. Jena ranks second with slightly more than half of the Dresden numbers, followed by Halle (36\% of the Dresden value), and Rostock (14\%).

A second observation regards the differences in the importance of public research. In Dresden and Jena, public research organizations account for more than one quarter of all patent applications. In Halle and Rostock, the shares of public research are about half 
as much. Compared to other German regions, these figures are very high. According to GREIF and SCHMIEDL (2002), in the period 1995-2000, only Berlin and Munich filed more patents from public research than Dresden, while Jena is ranked 6th. Among all 97 German planning regions, Dresden and Jena show the highest share of public research in all patent applications.

The high share of cooperations in Rostock is striking but probably due to the lack of corporate innovators and the accordingly high share of inventor applications, i.e. patents that are applied for by individuals who are also the inventors of the novel technical solution. Cooperative research in terms of research performed by teams of inventors then leads to a large number of cooperative linkages between individuals, whereas in other regions the co-researchers are more likely to work for one employer and we do not observe the relations within this single innovator.

\section{(TABLE 2 ABOUT HERE)}

One important concept for the analysis of actors in social networks is centrality. There are several concepts discussed in the literature but we will discuss only three of them at this point. ${ }^{5}$ The first and most simple idea is degree centrality, which is just the number of ties of an actor, denoted $d_{i}$. In our context, it is the number of transmission channels through which an actor can exchange knowledge with others. In the normalized version it is the number of ties of actor $i$ divided by the number of possible ties, $C_{D}(i)=d_{i} /(g-1)$, where $g$ is the size of the network. An actor can also be defined as being central if he "controls" knowledge flows between other actors. This betweenness centrality is based upon the frequency with which an actor is positioned between pairs of other actors on the shortest paths connecting them. More technically, if $g_{j k}$ is the number of shortest paths (geodesics) between actors $j$ and $k$ and $g_{j k}(i)$ the 
number of these paths that contain actor $i$, betweenness centrality of actor $i$ is then given as $C_{B}(i)=\sum_{j \neq i \neq k} \frac{g_{j k}(i)}{g_{j k}}$. The third concept considers the distance of an actor to all other actors in the network; the closer (shorter path length) one is to all others, the higher is his closeness centrality. The problem with this last measure is that in networks with unconnected components, it is difficult to determine the distance to actors who are not reachable, and therefore we do not use it here.

In the following, we describe the specificities of each of the four networks as revealed by the networks' graphical representations. The visualizations of the regional networks of innovators (figure 1 to figure 4) show the networks of personal relationships - cooperation and mobility combined - over the whole seven-year period 1995-2001 and should provide a general impression of the regional networks. Each innovator is represented by a node, where public research institutions are represented by square-shaped nodes and private firms or individuals by circles. The size of a node is proportional to the number of patents filed by the respective actor. Edges between the nodes represent cooperative relationships via joint patent application (dark-grey) or relationships via mobile inventors (light-grey). If two innovators have both types of relationships, edges are black. The width of the edges is proportional to the number of relations between the respective actors. The position of nodes and the length of the edges is produced by multidimensional scaling with node repulsion and equal edge length bias (BORGATTI et al., 2002). A direct interpretation is of course difficult, but more central actors are generally positioned at the center of the network. For the sake of readability, those nodes without any links to other nodes ("isolates") are omitted. Further, only the largest component is shown. A network component is defined as a subset of all network nodes in which there is a path between all pairs of nodes in the 
subset but no path to any node in other subsets (other components). For each region, detailed information about the most active patentees and their ranking based on degree and betweenness centrality is given in the working paper (GRAF and HENNING, 2006). This ranking provides the basis for our statements about actor centrality in the following network descriptions.

(FIGURE 1 ABOUT HERE)

Dresden The innovator network of Dresden (figure 1) can be characterized as bipolar. It is dominated by two large public research organizations, the FraunhoferGesellschaft and the Technical University (TU) Dresden, with highest ranks in terms of centrality and the number of patents filed. Koenig \& Bauer, a printing press manufacturer, has filed even more patents but ranks only 14th in terms of centrality. This company should be seen as a special case due to the fact that its products, huge printing machines for newspapers, often have the character of singular devices adapted to each customer's special needs where each single step of adaptation seems to be patentable. As all patents generated by one of the eleven Fraunhofer institutes located in Dresden are filed centrally at the society's headquarters in Munich, we cannot distinguish between different institutes. Taken as a single entity, these institutes appear as something like a second technical university (between whose departments we cannot differentiate either) covering many fields of research, especially in engineering disciplines.

The two central actors are strongly connected both by cooperative relationships and by scientists moving from one organization to the other. Each pole is the central actor of a subnet mainly consisting of private firms. The Fraunhofer subnet seems to be more tightly interconnected and more cooperative than the TU Dresden subnet. Between the 
two subnets there are few linkages. While there are some intermediates, such as the Rossendorf Research Institute (FZ Rossendorf) and the Institute for Solid State and Materials Research (IFW), most of the connections between the subnets stem from direct relations between the two big research organizations.

Seven out of the ten most central patentees are public research organizations, including the technical college (HTW Dresden) in the TU Dresden subnet and the Institute for Air-conditioning and Refrigeration Engineering (ILK) with a more independent position. The other three are Siemens, Infineon, and Bosch. The very strong connection between Siemens and Infineon is due to the fact that Infineon is a 1999 semiconductor spin-off of Siemens.

\section{(FIGURE 2 ABOUT HERE)}

Jena Different from Dresden, the network of innovators in Jena (figure 2) is multi-polar. The most active patentee is a private firm, Carl Zeiss, which is a successor of the former 'Kombinat' VEB Carl Zeiss which dominated the economic structure of Jena during the socialist era in the GDR. Carl Zeiss also ranks high in terms of centrality, but the most central actor of the network is the university (FSU Jena), followed by two public institutions of applied research, the Institute for Physical High Technology (IPHT) and the Fraunhofer-Gesellschaft. In contrast to Dresden, private companies such as Carl Zeiss, Jenoptik (another successor of the Kombinat), Jenapharm, and Schneider Laser are clearly visible actors and are tightly connected within the network. The same holds for non-university research institutes such as the Hermsdorf Institute for Technical Ceramics (HITK), the Thuringian Institute for Textile and Plastics Research (TITK), and the Hans-Knoell Institute. The linkages between all the central actors are dense and no separated subnets can be identified. The picture 
supports the assumption that Jena's lead in terms of patent efficiency might be the result of intense knowledge flows within the region's network of innovators.

\section{(FIGURE 3 ABOUT HERE)}

Halle In Halle (figure 3), Buna Sow Leuna, with 142 patents and first rank in terms of centrality, is the dominating actor, followed by Martin-Luther University (MLU) Halle-Wittenberg, the only research organization of importance, and the former Leuna-Works. In 1995, Dow Chemical took over the former Buna-Works, whereas Leuna was split up into several smaller firms, namely KataLeuna, Chemtec Leuna, and RMH Polymers. Strong (light-grey) ties between Leuna and its successors indicate that former Leuna researchers often work for (or are the founders of) the smaller firms which developed from former Leuna departments. The third important location of chemical industry, Bitterfeld-Wolfen, has its own subnet, too. The main actor here is FEW Chemicals. The ties between the three locations are not prominent. The university is connected with Buna Sow Leuna, but does not have direct ties with the Leuna or the Bitterfeld complex. The Leuna-Works apply for patents only until 1996, the year Buna Sow Leuna appears in the list for the first time

At large, the innovator network of Halle is more fragmented than those of Dresden or Jena. The actors forming the main component are organized in clusters, connected only through a few bridging actors ("cutpoints"), which makes the network vulnerable to breakup.

(FIGURE 4 ABOUT HERE)

Rostock In Rostock, patent activity is dominated by the Rostock university as the center of the main component. The university displays many cooperative (dark-grey) 
links to individual innovators, which is partly in consequence of the data refinement procedure by which individual applications of professors were assigned to the university. Presumably these professors often set their staff as co-applicants, resulting in cooperative links between the university and these staff members which are in fact intra-university relationships. But we cannot correct for this as it is nearly impossible to verify these persons as former university staff. Surrounding the university, a number of innovators are biotech firms, indicating some progress towards the officially promoted new focus on biomedical sciences. Engineering disciplines close to industries traditionally located in the region, such as machinery and shipbuilding, do not play a prominent role in the main component around the university, but still live on in the smaller components. Compared to the three other regions, the innovator network in Rostock is very small in size and faces a severe lack of private firm R\&D.

\subsection{Comparative Network Structures}

\subsubsection{Static Analysis}

The network visualizations presented above show only the largest component of the networks. General characteristics of the complete networks for the whole period (19952001) are given in table $3^{6}$. We report statistics on the connectedness (share of actors in the largest component and isolates) and general structure of the network (centralization) and on the intensity of interaction (density and mean degree).

Looking at the most comprehensive type of network, the network of personal relationships, we find that the main component comprises a share of all innovators ranging from $25 \%$ in Rostock to $37 \%$ in Jena. This order between the four regions is reversed when it comes to the share of isolated innovators, but the inter-regional variation is lower. Assuming that knowledge flows only occur between connected 
actors, in Jena more actors can participate in the sharing of common knowledge. The Jena network connects the highest share of innovators within the largest component and at the same time leaves the lowest share isolated. Rostock, by contrast, is least able to exploit its networking potential in terms of the share of actors in the largest component. The absolute size of the largest component is, of course, highest in Dresden.

\section{(TABLE 3 ABOUT HERE)}

With respect to the centralization of the networks ${ }^{7}$, i.e., the extent to which they are concentrated on one or few dominant actors, we observe that Rostock comes closest to the extreme of a "star". As the university is the only larger actor, this result is not really surprising. The network in Jena is also quite centralized, with a small core consisting of several large actors heavily interacting, as is Dresden with its bi-polar structure. The graphical impression of Halle corresponds well to the low centralization in this network, where the large actors are lined up like pearls on a string.

To analyze the intensity of interaction within a network, density is a widely used measure. If $g$ is the size of the network as measured by the number of actors and $d_{i}$ is the degree, i.e. the number of connections, of actor $i, i=1, \ldots, g$, then the density $D$ of the network is defined as the number of all active linkages divided by the number of possible linkages within the network $D=\left(\sum_{i=1}^{g} d_{i}\right) /\left(g^{2}-g\right)$. This measure is somewhat problematic in comparing networks of different sizes, as the number of possible linkages increases geometrically, while the actual number of linkages usually does not. As expected, the largest network (Dresden) is the one with the lowest density, while interaction in the small network of Rostock seems to be most intense. To account for this bias, we report the mean degree, i.e. the average number of ties, based on the actual 
number of connections and based on the dichotomized (binary) connections. The first measure takes into account the strength of relations and the second measure gives us the average number of related actors. With a mean degree of 6.483 , the actors in Jena are more interrelated than actors in the other regions. If we look at the number of linkages not accounting for intensity (i.e. based on the binary network), we find the actors in Halle to be connected to more different actors than elsewhere. The distinction between the types of relations reveals that the high level of connectedness in Halle is mainly based on linkages through scientist mobility, which is probably more the result of the reorganization processes mentioned above than to mobility in our - idealized interpretation.

\section{(FIGURE 5 ABOUT HERE)}

We present the size distribution of components in figure 5. A common feature of all networks is the existence of a single main component, which is at least ten times larger than the second largest component with a maximum size of 12 innovators in Halle and no more than 10 in the other regions (figure 5). This is somewhat remarkable, as the main component includes many different technological fields, and thus one might have expected to see several big components, each focused on one technology, or on a few related fields. Instead, the tendency to connect to a giant component does not seem to be hindered by the boundaries of disciplines, or, stated in a positive sense, we seem to observe cross-fertilization between innovators from different technologies. In all regional networks, we also observe a considerable share (12 to $16 \%$ ) of paired actors. To justify the identity of pairs of innovators as networking entities is obviously difficult. Sticking to the components with at least three connected actors reveals that, in Dresden, Jena and Halle, half of the patentees are embedded in one of these sub-networks. In Rostock, the share is slightly lower. 
So far we have inspected networks of personal relationships. We now disaggregate these networks and investigate relations through cooperation and mobility separately in figure 6 (see also table 3 ).

\section{(FIGURE 6 ABOUT HERE)}

In the network of personal relationships, a number of actors are connected only through paths that are composed of both cooperative (dark-grey) and mobility (lightgrey) links. These paths are broken up if we exclusively inspect cooperative, or mobility, relationships. By definition, this leads to smaller main components. But the extent to which the "combined" main component drops in size is dependent on the type of relationship. If innovators are linked only by scientist mobility, the largest components show up only slightly smaller. In Jena, the main component still includes $93 \%$ of its original actors. Even in Rostock, the main component is no less than $73 \%$ of its original size. If, on the other hand, only information about joint patent applications (cooperation) is used to build the networks, the main components drop sharply in size and comprise about half the original actors in Rostock and around $40 \%$ in Jena and Dresden. In Halle, the main component is only a $12 \%$ fraction of the combined main component. With 22 versus 12 innovators, the difference between the largest and the second largest component has nearly disappeared so that, in the case of the network of cooperative relationships in Halle, it is hard to speak of a main component at all.

It turns out that scientist mobility is more powerful in connecting innovators than is joint patenting. This is because mobility is more open and less formal - the innovators do not have to cooperate, nor do they even need to know each other. It is only the inventor moving from one employer (or, more general, innovator) to another that constitutes the link between the two. In contrast to cooperative patenting, reciprocity is 
not necessary. Instead, scientist mobility can even constitute a link between innovators who filed patents at opposite ends of the time period under inspection. Nevertheless, mobility relationships can still be a channel of knowledge transfer (ALMEIDA and KOGUT, 1999).

It is not only the main component that makes the difference between the two types of networks. The networks of cooperation are generally more scattered than the networks of scientist mobility. The share of isolated actors is slightly higher (exception: Rostock), and especially the share of pairs of innovators is about three times higher than in the networks of mobility (15-17\% compared to 5-6\%). In many cases, two actors just decide to file one or more joint patent(s), but do not cooperate with other actors within the period under inspection. On the other hand, if innovators are connected through joint inventors, it is less probable that the resulting component consists only of two innovators, since each inventor who moves to any other employer will add his new employer to the component. In consequence, the fraction of innovators in network components with at least three actors is generally higher in the networks linked by scientist mobility than in the networks linked by cooperative ties.

The higher cohesiveness of the networks of social mobility is also reflected in the generally higher number of connections to different partners, indicated by the binary mean degree, which is always larger for the mobility subnet than for the cooperative subnet. Compared with the cooperative networks, the networks of social mobility are also more centralized (exception: Rostock), i.e., they are more focused on a few dominant actors. A possible explanation is that research staff from universities and big firms is spread to smaller firms in the region. 


\subsubsection{Network Dynamics}

In general, the structure of the types of networks we analyze is highly dependent on the assumptions about the longevity of personal relations. In choosing a period from 1995 to 2001, we implicitly assume that, after seven years of having worked together, there are still connections between inventors. To check for the robustness of our results, we therefore also analyze shorter time spans of three years. In dividing the sample period into three overlapping sub-periods of equal length, 1995-1997, 1997-1999, and 19992001, we can also inspect network dynamics. In the following, we restrict ourselves to the combined network of personal relationships (figure 7 and table 6 in the appendix).

First of all, the regional networks show an increase in size,,as the number of nodes in later periods is always higher than in the preceding period. Whereas in Jena and Halle growth was higher between the first and the second period, Dresden and Rostock grew faster between the second and third period. Looking at the development over three periods, Rostock, starting at the smallest network size of 137 innovators in the first period, made the greatest step forward, with a 54\% growth in the number of innovators between the first and the third period. Jena, although starting at a size twice as large as Rostock, still realized a growth in the number of innovators of $42 \%$, which is also the greatest absolute increase $(+117)$. Halle started with a size not much smaller than Jena but grew only by $26 \%$. In Dresden, the number of patentees grew only by $16 \%$. Even if one accounts for the fact that Dresden has by far the largest pool of innovators, which leads to lower relative growth given the same absolute increase compared to regions with smaller-sized networks, the dynamic is still significantly lower than in the Jena region.

The growing number of innovators can be seen as a growing networking potential. 
To assess how far the regions actually use their potential, we have to look at the links between the network actors. The development of the largest component over time gives some hint about how network connectivity changes from period to period. In Jena, the share of the largest component in all network actors does not change between the second and the first periods, despite the significant growth in the number of innovators. However, in the last period, the share of the largest component in all actors rises impressively from $22 \%$ to $31 \%$ (a rise of $54 \%$ ). In Dresden, the share of the largest component rises continuously, but only up to a level of 23\%. Both Jena and Dresden manage to increase integration into the main component, despite a simultaneously growing number of actors.

In Halle and Rostock, the main component of the third period does not integrate as many actors as in the first period. In Halle, despite a relatively slow growing number of actors, the share of the largest component drops from $10 \%$ to $9 \%$. Besides this development, the absolute figures in Halle are of special interest. If we look at the whole period, there is almost no difference between Halle and Jena with respect to this measure. After splitting the period, we find the largest component in Halle to be broken up, which documents the fragility of this network mentioned above. In Rostock, a fast growing number of patentees cannot fully be integrated into the main component at the same time. This leads to a decrease in the share of main component from $21 \%$ in the first to $16 \%$ in the third period.

(FIGURE 7 ABOUT HERE)

If we compare the first and the last period, we observe an increasing centralization in Dresden and Jena, while the networks in Halle and Rostock become less dominated by few main actors. The mean degree increases significantly only in Jena (from 4.0 to 
5.2) and remains almost constant in Dresden and Rostock, while it decreases in Halle. If we only count the related actors but not the intensity of the link, we find an increasing mean degree in all regions except Dresden.

To summarize our descriptive results, we can state that all four networks have grown but the structural differences between regions are evident: i) only in Dresden and Jena do we observe that an increasing share of actors is integrated in the largest component, ii) the average number of linkages is only increasing in Jena, iii) Dresden and Jena become more centralized, while Halle and Rostock become more dispersed, iv) Dresden and Jena are especially dominated by public research. Dresden is a bi-polar network especially dominated by public research; in Jena, a group of core actors is wellbalanced between public research and private firms; in Halle, large firms dominate; and in Rostock, there is a rather central university and a mixture of individuals and smaller patenting firms.

It seems as if there is a relationship between the prevalence of valuable public research and the connectedness of local innovator networks. To assess this relationship in greater depth, we now turn to the specific role of public research.

\section{Research Institutions as Distinguished Network Actors}

Academic research has been identified as an important source of economic growth and the functions that are being served by these research institutions are various (SALTER and MARTIN, 2001). In general, they are expected to increase the stock of useful knowledge, train skilled graduates and transfer knowledge to industry. In addition, especially universities are becoming increasingly entrepreneurial, where the formation of academic start-ups and closer interaction with industry is added to their portfolio of functions (ETZKOWITZ, 1998). Within this study, we are able to shed some light on 
some of these functions, namely the education of skilled labour and spin-offs (mobility network) and the cooperation with private firms (cooperation network).

To assess the importance of public research for local innovation activity based on patent data, one fundamental point has to be stressed in the beginning. As stated in section 2, patents are granted for new solutions to technical problems. To produce patentable knowledge, a scientific discipline has to be, in principle, applicable and technical in nature. Therefore, large university faculties such as social sciences, cultural studies, and arts, though potentially of considerable importance for a region's economic success by providing organizational know-how and creativity (FLORIDA, 2002), are not within the scope of this investigation. The same holds for research institutes explicitly designed to perform basic research, namely the Max-Planck institutes: Despite being well-funded and staffed, they hardly show up in the networks of innovators based on patent information. In contrast, the Fraunhofer institutes, with their mission of applied research and the need to partly finance themselves through contract research for private firms, are important patentees.

Furthermore, even if we stick to the fields of research where patent output is to be expected, networks built from patent relations still reflect just a fraction of the interaction actually going on between public research and private firms. Aside from measurement problems already discussed in section 3 , this is because a wide variety of informal contacts as well as contract research activities just do not lead to (and are not aimed at) patent output.

The above-mentioned points hold for purely private relationships as well, but to a lesser extent: As they are forced to survive in the market, private firms perform generally more applied research and have higher incentives to protect results from R\&D 
by patents. Consequently, when interpreting the role of public research within networks of patent innovators, one should keep in mind that their importance is systematically underestimated both in terms of the absolute amount of knowledge transfer and relative to exclusively private relationships.

We already discussed the centrality measures in section 4 and now use these individual centrality measures based on degree and on betweenness. By counting the direct links between a node and its neighbors, the degree-based centrality measure provides us with an idea of how connected an actor is. The betweenness measure tells us how important an actor is for knowledge flows between other, different actors, and therefore for the connectivity of the network as a whole (FREEMAN, 1978). From rankings of the network members according to these measures, we know that Dresden and Jena are dominated by public research, while in Halle and Rostock, this is not so clear. $^{8}$

For a more systematic approach to analyzing the differences between public and private actors in terms of centrality, we calculate average scores for both types of actors (private and public) (see table 4). It becomes evident that, in all regions and for all types of networks, public actors are more central than private ones, according to degree as well as betweenness centrality.

\section{(TABLE 4 ABOUT HERE)}

Of course, centrality and especially degree centrality is not independent of the size of innovators. Under the assumption that the probability for cooperation per unit of economic activity is given, we should expect large actors, characterized by a relatively large amount of economic activity, to cooperate more frequently than smaller enterprises (FRITSCH and LUKAS, 2001). Large organizations are also characterized 
by a large work force, and absolute labor turnover, which is the basis for linkages through mobility, should then be higher for these actors. Consequently, we expect larger actors to have more linkages through cooperation and mobility.

Public research institutes are, in general, larger than the average innovator, which might lead to our observation of a higher centrality of public research. To control for this effect, we perform a simple OLS regression with degree centrality as the dependent variable (table 5). The independent variables are a dummy variable for public institutions (Public) and a proxy for size. Since we cannot observe size directly, we approximate size by the number of patents filed by each innovator (Patents). In all regressions, the number of patents has a significant explanatory power for centrality. In Dresden and Jena, the positions of public research are also significantly more central than those of private actors. In Halle, this only holds for the overall network of personal relations and the network of cooperation, while in the mobility network the coefficients of the Public dummy are positive but not significant. In Rostock, public actors seem to be more central than their private counterparts in all networks, but again, the differences are not significant.

\section{(TABLE 5 ABOUT HERE)}

Why are public research organizations still more central network actors even if size differences have been taken into account? First, what really matters may not be size but the diversity and variety of research conducted, which makes them a promising knowledge source for a great number of private firms specialized in very different business areas. This holds especially for the big research universities that are by definition 'universal'. Second, public research organizations might be more willing to cooperate and share their knowledge. This would be in line with DASGUPTA and 
DAVID's (1994) concept of 'open science', where disclosure and diffusion of research results are seen as the original mission and fundamental norm of public research. This again holds first of all for universities. Third, and less idealistic, it may just be the need for financial capital that forces public research institutions to seek for contract research partners. This is most apparent for non-university public research institutes, e.g., the institutes of the Fraunhofer-Gesellschaft, which are only partly supported by public funds. Patent cooperations can then be seen as aiming at the joint marketing of new knowledge. Public research organizations act as substitutes for private research service providers, and the observed patent relations are just tracing their business relationships.

\section{Conclusion}

This work is an exploratory study with the goal of analyzing differences between regional innovation systems by applying social network analysis methods based on patent data. While we are confident that our approach provides valuable insights into structures of interaction and knowledge flows within regional innovation systems, we are also aware of its shortcomings. The major issue is the bias due to differences in patenting propensities between industries. A region might have comparative advantages in industries where patenting is not commonplace and therefore many actors and linkages remain unexplored. Our interpretations have therefore to be seen in light of these restrictions.

Our first impressions of the networks and its actors led our research towards investigating the role of public research. It became clear that two regions, Dresden and Jena, perform quite well with respect to innovative efficiency. The innovator networks in these two regions differ from the other two networks, Halle and Rostock, as they integrate a larger share of the innovating actors. They have also been able to increase 
this share over time, and their networks show growing centralization. At the same time, public research organizations seem to be especially prominent within these two networks.

With respect to the role of public research, our results can be summarized in two points i) universities and public research institutions are significantly more central, i.e., more interconnected within innovator networks, than private actors, ii) there are differences between regions with respect to the centrality of public research. While in Dresden and Jena, the institutions of public research seem to fulfil their function quite well, public research in Halle and Rostock is found to be less integrated.

Our research provides exemplary evidence that public research organizations which are well-connected within the local network of innovators are crucial for regional innovative performance. It is only through cooperating and interacting that their genuine occupation with generating new knowledge and collecting external knowledge becomes fruitful for the region. While the education of skilled labour is most important for the long-term increase in regional absorptive capacity, well-connected actors of public research provide direct input of relevant knowledge for the regional economy.

Acknowledgements - The authors thank Guido Bünstorf, Uwe Cantner, Michael Fritsch, Michael Nippa and Viktor Slavtchev as well as two anonymous referees for valuable comments. Former versions of the paper were presented at seminars in Jena and Freiberg, at the 11th Conference of the International J. A. Schumpeter Society in Sophia-Antipolis, 2006, and at the Jahrestagung of the Verein für Socialpolitik in Bayreuth, 2006. The usual disclaimer applies.

\section{Notes}

${ }^{1}$ Data are from the establishment file of the German Social Insurance Statistics, which does not allow the 
aggregation of information to the firm level. See FRITSCH and BRIXY (2004) for a detailed description of the database.

${ }^{2}$ SCOTT (2000) provides a very good introduction to social network analysis.

${ }^{3}$ Following BALCONI et al. (2004), we use the term 'innovator' to avoid confusion with the term 'inventor' which is used for the scientists and engineers involved in the process of novelty creation. Of course, we do not know, whether the patent applications lead to a marketable product.

${ }^{4}$ The way mobility is measured, it might also include cases of inventors performing contract research for different innovators without actually being employed, e.g., technical consultants.

${ }^{5}$ For a detailed discussion of the concept of centrality, please refer to FREEMAN (1978-1979) or WASSERMANN and FAUST (1994).

${ }^{6}$ For details on the calculation of nework statistics, please refer to the widely cited book by WASSERMANN and FAUST (1994).

${ }^{7}$ The network centralization is given by $C=\frac{\sum_{i=1}^{g}\left(\max C_{D}(i)-C_{D}(i)\right)}{g-2}$, where $C_{D}(i)$ is the normalized degree centrality.

${ }^{8}$ Within the top ten central actors, there appear only three (Dresden) and two (Jena) private actors, respectively. The rankings are reported in the working paper version (GRAF and HENNING, 2006). 


\section{References}

ALMEIDA P. and KOGUT B. (1999) Localization of knowledge and the mobility of engineers in regional networks, Management Science 45, 905-917.

ARUNDEL A. and KABLA I. (1997) What percentage of innovations are patented? Empirical estimates for European firms, Research Policy 27, 127-141.

BALCONI M., BRESCHI S. and LISSONI F. (2004) Networks of inventors and the role of academia: An exploration of Italian patent data, Research Policy 33, 127145.

BORGATTI S., EVERETT M. and FREEMAN L. (2002) Ucinet for Windows: Software for Social Network Analysis. Analytic Technologies, Harvard.

BOSCHMA R. (2005) Proximity and innovation: A critical assessment, Regional Studies 39, 61-74.

BRESCHI S. and LISSONI F. (2003) Mobility and Social Networks: Localised Knowledge Spillovers Revisited, CESPRI Working Paper No. 142, Centro di Ricerca sui Processi di Innovazione e Internazionalizzazione (CESPRI), Milan.

BRESCHI S. and LISSONI F. (2004) Knowledge Networks from Patent Data: Methodological Issues and Research Targets, CESPRI Working Paper, No. 150, Centro di Ricerca sui Processi di Innovazione e Internazionalizzazione (CESPRI), Milan.

BROUWER E. and KLEINKNECHT A. (1999) Innovative output, and a firm's propensity to patent. An exploration of CIS micro data, Research Policy 28, 615624. 
BURT R. S. (1983) Studying status/role-sets using mass surveys, Applied Network Analysis: A Methodological Introduction, Sage, Beverly Hills, CA (Chapter 5).

CAPELLO R. and FAGGIAN A. (2005) Collective learning and relational capital in local innovation processes, Regional Studies 39, 75-87.

CANTNER U. and GRAF H. (2006) The network of innovators in Jena: An application of Social Network Analysis, Research Policy 35, 463-480.

COOKE P. (1998) Introduction: Origins of the concept, in Braczyk H.-J., Cooke P. and Heidenreich M. (Eds) Regional innovation systems: The role of governances in a globalized world, pp. 2-25. UCL Press, London.

COSTENBADER E. and VALENTE T. W. (2003) The stability of centrality measures when networks are sampled, Social Networks 25, 283-307.

DASGUPTA P. and DAVID P. A. (1994) Toward a new economics of science, Research Policy 23, 487-521.

EDQUIST C. (1997) Systems of innovation approaches - their emergence and characteristics, in Edquist C. (Ed) Systems of innovation: Technologies, institutions and organizations, pp. 1-35, Pinter, London.

ETZKOWITZ H. (1998) The norms of entrepreneurial science: cognitive effects of the new university-industry linkages, Research Policy 27, 823-833.

FLEMING L., COLFER L., MARIN A. and MCPHIE J. (2004) Why the valley went first: Agglomeration and emergence in regional inventor networks, forthcoming in Padgett J. and Powell W. (Eds) Market emergence and transformation. MIT Press, Cambridge. 
FLEMING L., KING III C. and JUDA A. (2006) Small worlds and regional innovation, SSRN eLibrary, 892871.

FLORIDA R. (2002) Bohemia and economic geography, Journal of Economic Geography 2, 55-71.

FREEMAN L. C. (1978-1979) Centrality in social networks conceptual clarification, Social Networks 1, 215-239.

FRITSCH M. (2001) Co-operation in regional innovation systems, Regional Studies 35, 297-307.

FRITSCH M. and LUKAS R. (2001) Who cooperates on R\&D?, Research Policy 30, 297-312.

FRITSCH M. and SCHWIRTEN C. (1999) Enterprise-university co-operation and the role of public research institutions in regional innovation systems, Industry and Innovation 6, 69-83.

Formatted: Font: Italic

FRITSCH M. and SLAVTCHEV V. (2005) The role of regional knowledge sources for innovation, Freiberg Working Papers No. 15-05, Faculty of Economics and Business Administration, Technical University Bergakademie Freiberg.

FRITSCH M. and BRIXY U. (2004) The establishment file of the German social insurance statistics, Schmollers Jahrbuch/Journal of Applied Social Science Studies 124, 183-190.

GRAF H. AND HENNING, T. (2006) Public Research in Regional Networks of 
JAFFE A. B., TRAJTENBERG M. and HENDERSON R. (1993) Geographic localization of knowledge spillovers as evidenced by patent citations, Quarterly Journal of Economics 108, 577-598.

LUNDVALL B.-Å. (ed.) (1992) National Systems of Innovation: Towards a Theory of Innovation and Interactive Learning, Pinter Publishers, London.

LUNDVALL B.-Å. and JOHNSON B. (1994) The learning economy, Journal of Industry Studies 1, 23-42.

MALMBERG A. and MASKELL P. (2006) Localized learning revisited, Growth and Change 37, 1-18.

NELSON R. R. (ed.) (1993) National Innovation Systems: A Comparative Analysis, Oxford University Press, New York.

PAVITT K. (1985) Patent statistics as indicators of innovative activities: possibilities and problems, Scientometrics 7 (1-2), 77-99.

MAIRESSE J. and MOHNEN (2003) Intellectual property in services: What do we learn from innovation surveys? In OECD (Ed) Patents, innovation and economic performance, pp. 227-245. OECD, Paris. 
SALTER A. J. and MARTIN B. R. (2001) The economic benefits of publicly funded basic research: a critical review, Research Policy 30, 509-532.

SCOTT J. (2000) Social Network Analysis: A Handbook, 2nd edition, Sage Publications, London.

SINGH J. (2003) Social networks as drivers of knowledge diffusion, Harvard University, mimeo.

SINGH J. (2005) Collaborative networks as determinants of knowledge diffusion patterns, Management Science 51, 756-770.

WASSERMANN S. and FAUST K. (1994) Social Network Analysis: Methods and Applications, Cambridge University Press, Cambridge.

\section{Appendix}

(TABLE 6 ABOUT HERE) 


\section{Tables}

Table 1: Regional innovative potential and patent output (mean yearly values)

\begin{tabular}{|c|c|c|c|c|}
\hline & Dresden & Jena & Halle & Rostock \\
\hline Population (1994-2000) & $1,035,486$ & 794,471 & 893,614 & 438,643 \\
\hline \multicolumn{5}{|l|}{ Private sector $\left(1994-2000^{\mathrm{a}}\right)$} \\
\hline Establishments $^{\mathrm{b}}$ & 26,976 & 20,059 & 19,775 & 10,923 \\
\hline Employees & 291,791 & 201,167 & 226,668 & 111,401 \\
\hline natural scientists and engineers ${ }^{\mathrm{c}}$ & $4.13 \%$ & $2.57 \%$ & $3.08 \%$ & $2.60 \%$ \\
\hline \multicolumn{5}{|l|}{ Universities $^{\mathrm{d}}$ (1994-2000) } \\
\hline Total research and teaching staff & 3,775 & 2,633 & 2,642 & 1,741 \\
\hline In natural sciences and engineering ${ }^{\mathrm{e}}$ & $58 \%$ & $35 \%$ & $42 \%$ & $38 \%$ \\
\hline Professors & 704 & 452 & 425 & 289 \\
\hline In natural sciences and engineering & $64 \%$ & $43 \%$ & $44 \%$ & $49 \%$ \\
\hline \multicolumn{5}{|l|}{ Patents (1995-2001) } \\
\hline per year & 467.0 & 253.7 & 167.0 & 67.1 \\
\hline per 100,000 inhabitants & 45.1 & 31.9 & 18.7 & 15.3 \\
\hline per 1,000 employees $^{f}$ & 1.16 & 0.94 & 0.53 & 0.42 \\
\hline per 1,000 natural scientists and engineers & 32.0 & 38.1 & 21.0 & 17.3 \\
\hline
\end{tabular}

${ }^{a}$ Natural scientists and engineers in Dresden: 1996-2000.

${ }^{\mathrm{b}}$ Includes all establishments with at least one employee.

${ }^{\mathrm{c}}$ Employees with tertiary education in natural science or engineering.

d Includes research universities and technical colleges ("Fachhochschulen").

${ }^{\mathrm{e}}$ Includes three groups of scientific disciplines: natural sciences, agricultural and nutritional sciences, and engineering. Excludes medical sciences, cultural and social sciences, law and economics, and arts.

${ }^{\mathrm{f}}$ Total of private and public sector.

Source: German statistical office (population, university staff), establishment file of the German Social Insurance Statistics (establishments, employees), German patent office (patents). 
Table 2: Regional patenting and network actors

\begin{tabular}{lrrrr}
\hline & Dresden & Jena & Halle & Rostock \\
\hline Patents & & & & \\
\hline Number of applications & 3,269 & 1,776 & 1,169 & 470 \\
$\quad$ co-applications & $10.5 \%$ & $13.3 \%$ & $13.2 \%$ & $19.8 \%$ \\
by private actors & $74.5 \%$ & $72.3 \%$ & $87.6 \%$ & $86.7 \%$ \\
$\quad$ by public research & $25.5 \%$ & $27.7 \%$ & $12.4 \%$ & $13.3 \%$ \\
\hline Actors & & & & \\
\hline Applicants & 1,132 & 679 & 538 & 350 \\
$\quad$ Private actors & 1,078 & 629 & 511 & 336 \\
$\quad$ Public research & 54 & 50 & 27 & 14 \\
Inventors & 4,127 & 2,686 & 1,682 & 614 \\
\hline
\end{tabular}


Table 3: Characteristics of regional innovator networks in the period 1995-2001

\begin{tabular}{lrrrrrr}
\hline & \multicolumn{3}{c}{ Dresden } & \multicolumn{4}{c}{ Jena } \\
\cline { 2 - 7 } & $\begin{array}{c}\text { Personal } \\
\text { Relationships }\end{array}$ & & & \multicolumn{5}{c}{ Personal } & Cooperation Mobility \\
& 1,132 & 1,132 & 1,132 & 679 & 679 & 679 \\
Nodes & $30.9 \%$ & $12.0 \%$ & $26.7 \%$ & $37.4 \%$ & $15.0 \%$ & $34.8 \%$ \\
Share in largest component & $35.8 \%$ & $58.0 \%$ & $55.6 \%$ & $32.7 \%$ & $55.1 \%$ & $52.3 \%$ \\
Share of isolates & 0.094 & 0.052 & 0.067 & 0.114 & 0.037 & 0.098 \\
Network centralization & 0.004 & 0.003 & 0.002 & 0.010 & 0.006 & 0.004 \\
Density & 5.083 & 3.081 & 2.002 & 6.483 & 3.935 & 2.548 \\
Mean degree & 2.231 & 0.820 & 1.429 & 2.695 & 0.919 & 1.817 \\
Mean degree (binary) & & & & & &
\end{tabular}

\begin{tabular}{|c|c|c|c|c|c|c|}
\hline & Halle & & & Rostock & & \\
\hline & $\begin{array}{r}\text { Personal } \\
\text { Relationships }\end{array}$ & Cooperation & Mobility & $\begin{array}{r}\text { Personal } \\
\text { Relationships }\end{array}$ & Cooperation & Mobility \\
\hline Nodes & 538 & 538 & 538 & 350 & 350 & 350 \\
\hline Share in largest component & $34.9 \%$ & $4.1 \%$ & $30.5 \%$ & $25.1 \%$ & $12.3 \%$ & $18.3 \%$ \\
\hline Share of isolates & $35.9 \%$ & $58.7 \%$ & $52.6 \%$ & $37.4 \%$ & $51.4 \%$ & $63.4 \%$ \\
\hline Network centralization & 0.050 & 0.021 & 0.048 & 0.144 & 0.118 & 0.046 \\
\hline Density & 0.011 & 0.006 & 0.005 & 0.014 & 0.010 & 0.005 \\
\hline Mean degree & 6.093 & 3.230 & 2.862 & 5.034 & 3.434 & 1.600 \\
\hline Mean degree (binary) & 3.022 & 0.803 & 2.230 & 2.200 & 1.006 & 1.194 \\
\hline
\end{tabular}


Table 4: Comparing centrality of public and private actors

\begin{tabular}{lrrrrr}
\hline & & Degree & \multicolumn{3}{c}{ Betweenness $^{\mathrm{a}}$} \\
\cline { 3 - 6 } Network of & Private & Public & Private & Public \\
personal relations & Dresden & 4.2 & 22.2 & 89.2 & $3,389.3$ \\
& Jena & 4.8 & 27.3 & 96.6 & $1,485.0$ \\
& Halle & 5.8 & 12.6 & 146.0 & $1,279.9$ \\
& Rostock & 4.5 & 18.1 & 22.5 & 527.6 \\
\hline Network of & Dresden & 2.5 & 15.2 & 3.5 & 656.3 \\
cooperations & Jena & 2.8 & 17.7 & 6.9 & 355.5 \\
& Halle & 3.0 & 7.1 & 1.0 & 21.1 \\
& Rostock & 3.0 & 14.2 & 0.1 & 118.3 \\
Network of & Dresden & 1.8 & 7.0 & 114.3 & $2,406.8$ \\
mobility & Jena & 2.0 & 9.6 & 108.3 & $1,219.3$ \\
& Halle & 2.7 & 5.5 & 131.1 & 705.2 \\
& Rostock & 1.5 & 3.9 & 25.7 & 198.6 \\
\hline a & & & & &
\end{tabular}

$\overline{{ }^{a} \text { dichotomized networks }}$

2 
Table 5: Influence of actor type and size on degree centrality in different networks

\begin{tabular}{|l|r|r|r|r|r|r|r|r|r|r|r|r|r|r|r|}
\hline & \multicolumn{3}{|c|}{ Network of personal relations } & \multicolumn{3}{|c|}{ Network of cooperation } & \multicolumn{4}{|c|}{ Network of mobility } \\
\hline & $\begin{array}{r}\text { Dresde } \\
\mathrm{n}\end{array}$ & Jena & Halle & Rostock & & & $\begin{array}{r}\text { Dresde } \\
\mathrm{n}\end{array}$ & Jena & Halle & $\begin{array}{r}\text { Rostoc } \\
\mathrm{k}\end{array}$ & $\begin{array}{r}\text { Dresde } \\
\mathrm{n}\end{array}$ & $\begin{array}{r}\text { Jena } \\
\text { Halle }\end{array}$ & $\begin{array}{r}\text { Rostoc } \\
\mathrm{k}\end{array}$ \\
\hline Constant & 5.883 & 4.513 & 8.626 & 0.234 & 3.194 & 2.872 & 4.511 & -1.459 & 2.689 & 1.640 & 4.115 & 1.693 \\
\hline & $(0.000)$ & $(0.000)$ & $(0.000)$ & $(0.804)$ & & $(0.000)$ & $(0.000)$ & $(0.000)$ & $(0.088)$ & & $(0.000)$ & $(0.000)$ & $(0.000)$ & $(0.000)$ \\
\hline Public & 22.544 & 27.769 & 9.323 & 7.786 & & 16.266 & 20.337 & 5.794 & 6.006 & & 6.277 & 7.432 & 3.529 & 1.780 \\
\hline & $(0.000)$ & $(0.000)$ & $(0.006)$ & $(0.065)$ & & $(0.000)$ & $(0.000)$ & $(0.010)$ & $(0.114)$ & $(0.000)$ & $(0.000)$ & $(0.079)$ & $(0.319)$ \\
\hline Patents & 0.976 & 2.078 & 1.201 & 5.393 & & 0.667 & 1.135 & 0.645 & 4.580 & & 0.309 & 0.943 & 0.557 & 0.813 \\
\hline & $(0.000)$ & $(0.000)$ & $(0.000)$ & $(0.000)$ & $(0.000)$ & $(0.000)$ & $(0.000)$ & $(0.000)$ & & $(0.000)$ & $(0.000)$ & $(0.000)$ & $(0.000)$ \\
\hline R2 & 0.381 & 0.624 & 0.227 & 0.523 & & 0.322 & 0.468 & 0.161 & 0.491 & & 0.289 & 0.656 & 0.147 & 0.125 \\
\hline adj. R2 & 0.380 & 0.623 & 0.224 & 0.520 & & 0.321 & 0.466 & 0.158 & 0.488 & & 0.288 & 0.655 & 0.144 & 0.120 \\
\hline Obs. & 1,132 & 679 & 538 & 350 & & 1,132 & 679 & 538 & 350 & & 1,132 & 679 & 538 & 350 \\
\hline
\end{tabular}

$\mathrm{P}$-values in parentheses. 
Table 6: Changing characteristics of the network of personal relations

\begin{tabular}{lrrrrrr}
\hline & Dresden & \multicolumn{5}{c}{ Jena } \\
\cline { 2 - 7 } & $1995-97$ & $1997-99$ & $1999-2001$ & $1995-97$ & $1997-99$ & $1999-2001$ \\
\hline Nodes & 527 & 535 & 613 & 281 & 367 & 398 \\
Share in largest component & $15.0 \%$ & $17.8 \%$ & $22.5 \%$ & $21.4 \%$ & $21.5 \%$ & $30.7 \%$ \\
Share of isolates & $44.4 \%$ & $45.8 \%$ & $45.0 \%$ & $43.4 \%$ & $43.9 \%$ & $39.2 \%$ \\
Network centralization & 0.070 & 0.060 & 0.081 & 0.056 & 0.073 & 0.101 \\
Density & 0.007 & 0.006 & 0.006 & 0.014 & 0.012 & 0.013 \\
Mean degree & 3.556 & 3.110 & 3.667 & 4.000 & 4.431 & 5.171 \\
Mean degree (binary) & 1.423 & 1.196 & 1.409 & 1.495 & 1.520 & 1.965 \\
\hline
\end{tabular}

\begin{tabular}{lrrrrrr}
\hline & Halle & \multicolumn{5}{c}{ Rostock } \\
\cline { 2 - 7 } & $1995-97$ & $1997-99$ & $1999-2001$ & $1995-97$ & $1997-99$ & $1999-2001$ \\
\hline Nodes & 238 & 273 & 300 & 137 & 152 & 211 \\
Share in largest component & $10.1 \%$ & $15.0 \%$ & $9.0 \%$ & $21.2 \%$ & $17.8 \%$ & $16.1 \%$ \\
Share of isolates & $41.2 \%$ & $45.8 \%$ & $45.7 \%$ & $46.0 \%$ & $40.1 \%$ & $39.3 \%$ \\
Network centralization & 0.065 & 0.039 & 0.053 & 0.160 & 0.126 & 0.122 \\
Density & 0.020 & 0.014 & 0.014 & 0.030 & 0.022 & 0.020 \\
Mean degree & 4.681 & 3.780 & 4.253 & 4.117 & 3.382 & 4.246 \\
Mean degree (binary) & 1.714 & 1.546 & 2.167 & 1.620 & 1.289 & 1.716 \\
\hline
\end{tabular}




\section{Figures}

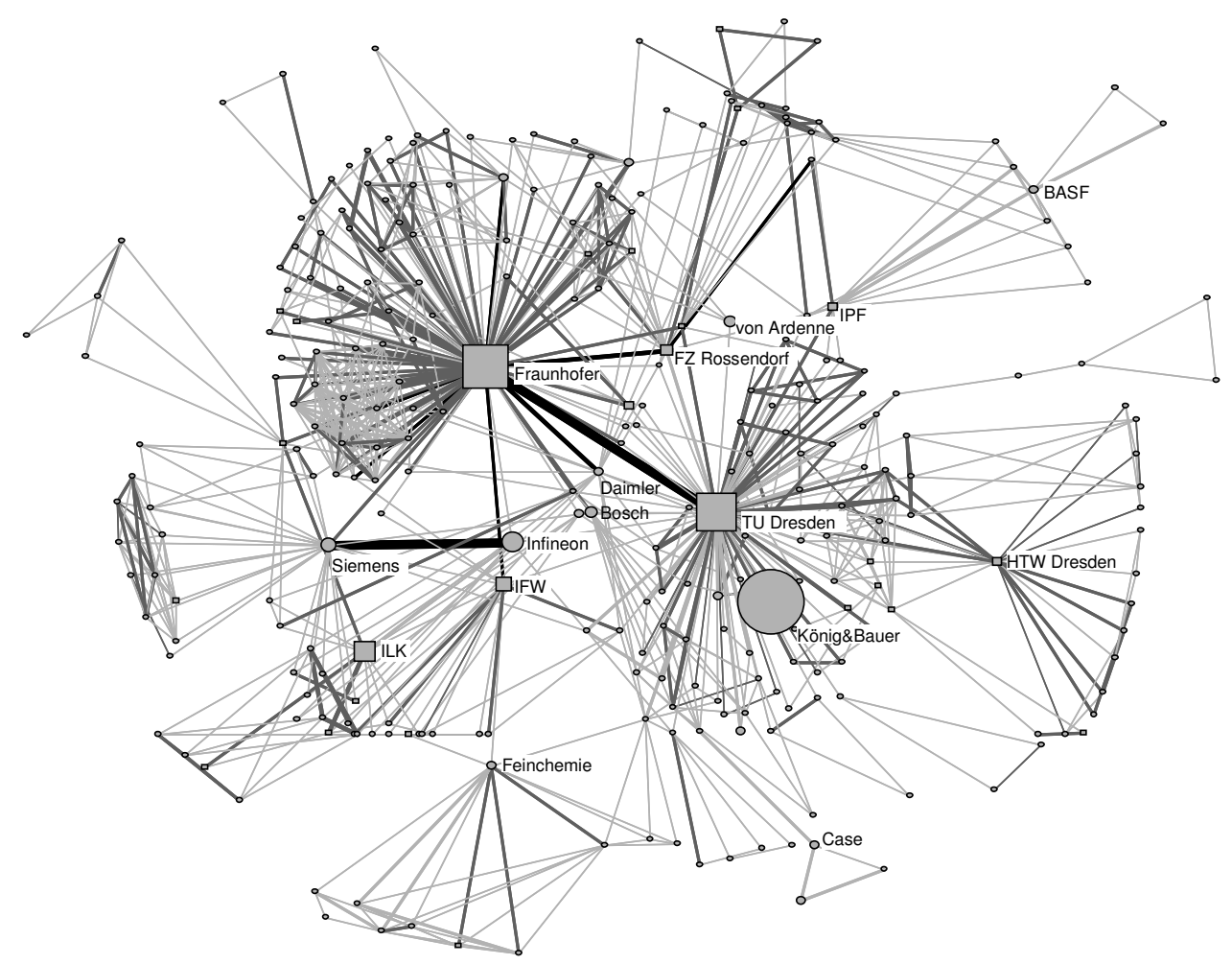

Note: Cooperations are dark-grey, scientist mobility is light-grey, and if both are present, lines are black

Figure 1: Main component of Dresden 1995-2001 


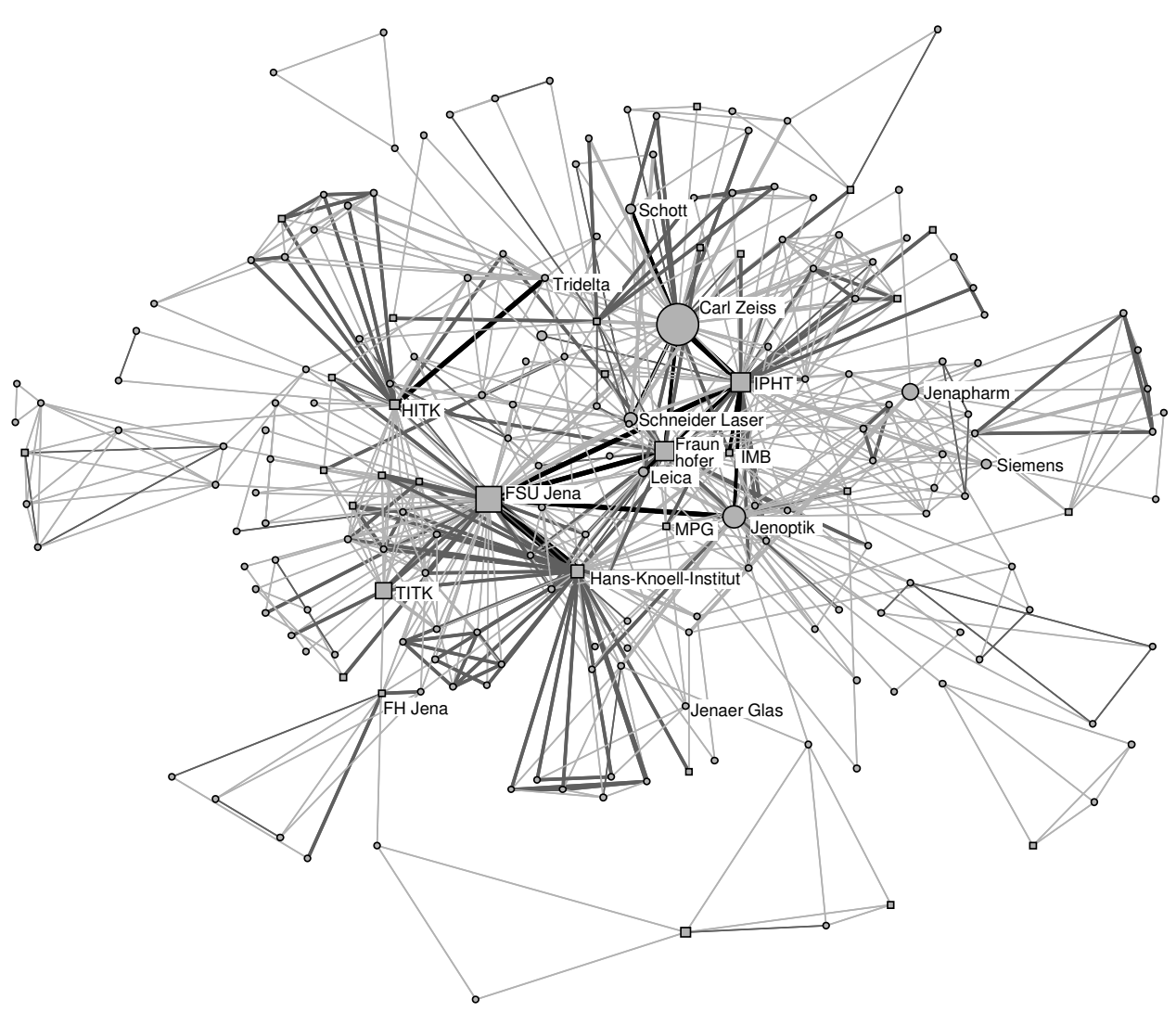

Note: Cooperations are dark-grey, scientist mobility is light-grey, and if both are present, lines are black

Figure 2: Main component of Jena 1995-2001 


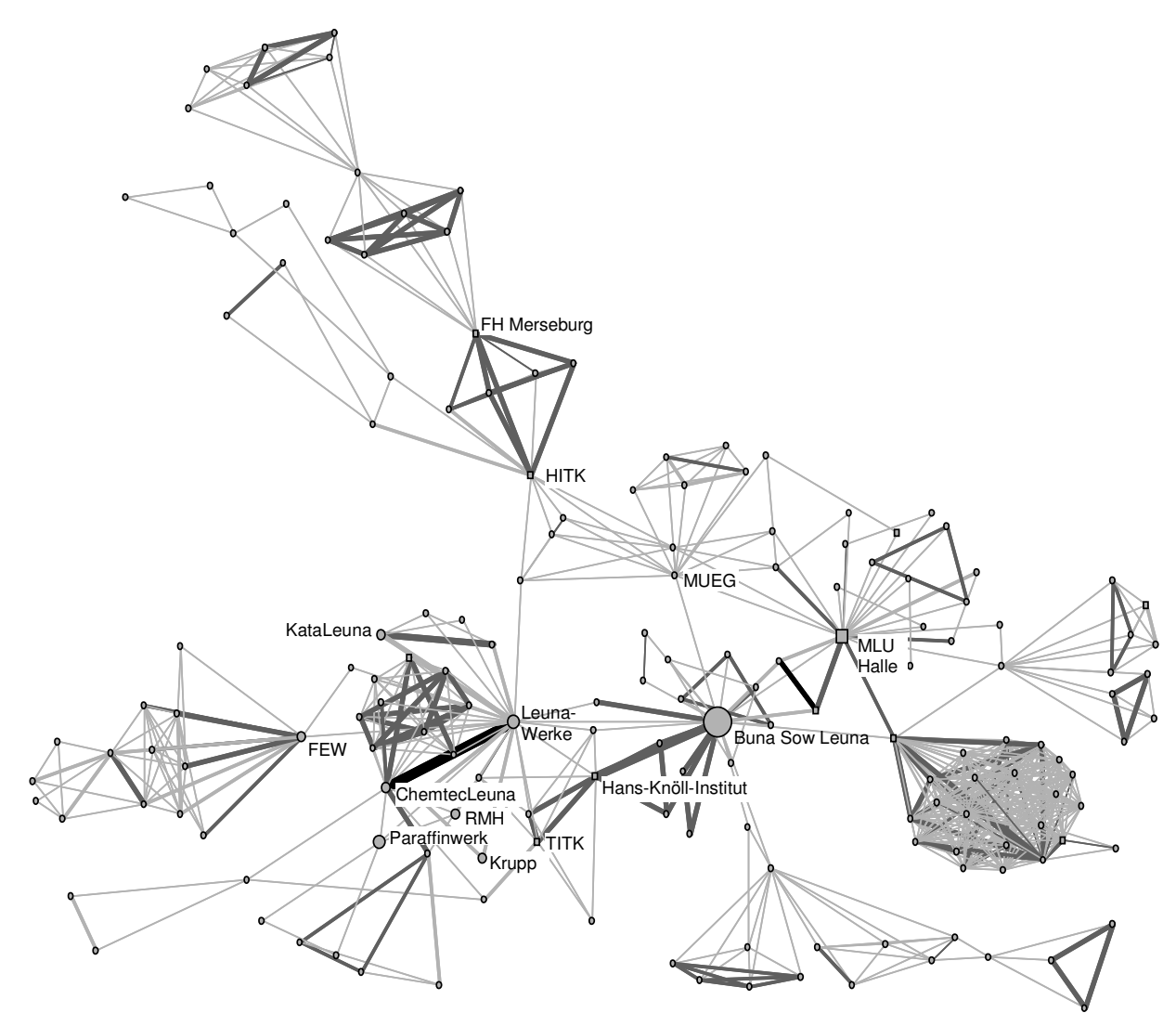

Note: Cooperations are dark-grey, scientist mobility is light-grey, and if both are present, lines are black

Figure 3: Main component of Halle 1995-2001 
1

2

3

4

5

6

7

8

9

10

11

12

13

14

15

16

17

18

19

20

21

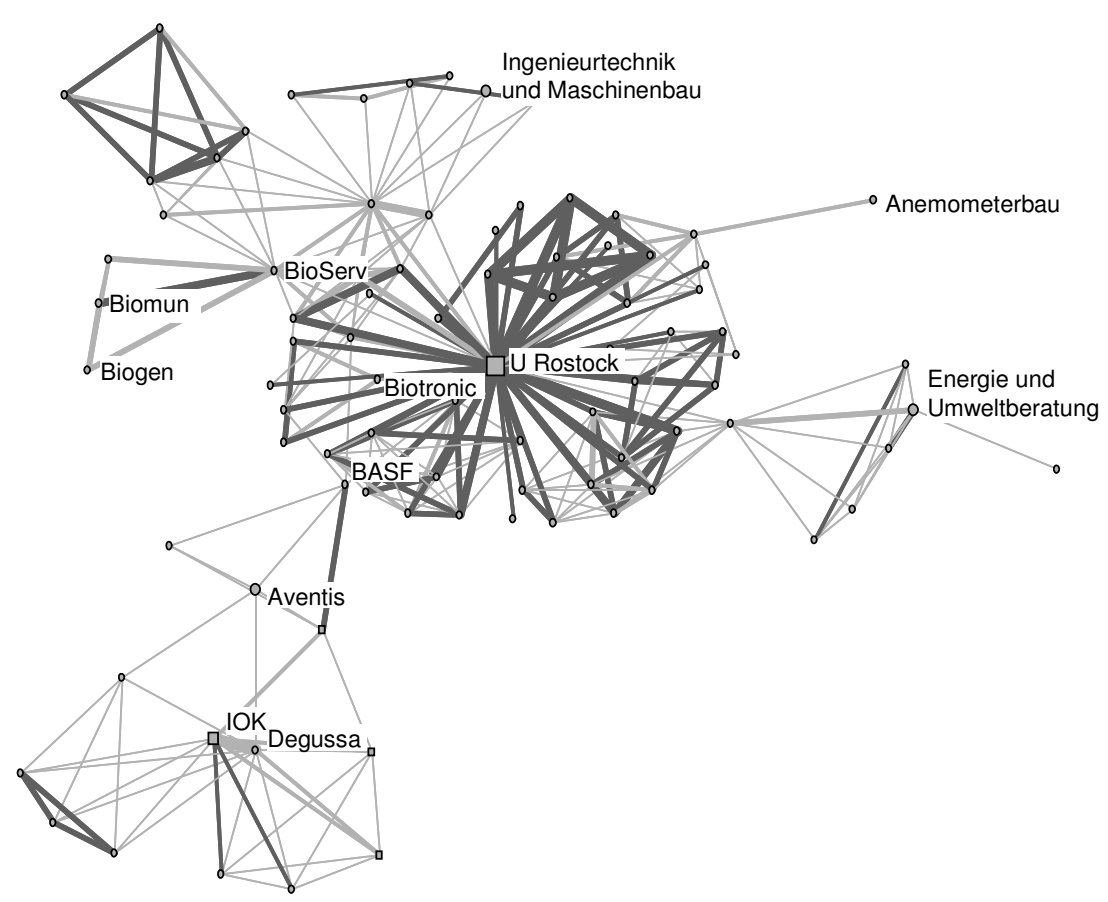

Note: Cooperations are dark-grey, scientist mobility is light-grey, and if both are present, lines are black

Figure 4: Main component of Rostock 1995-2001 


\section{Innovators}

(Share)

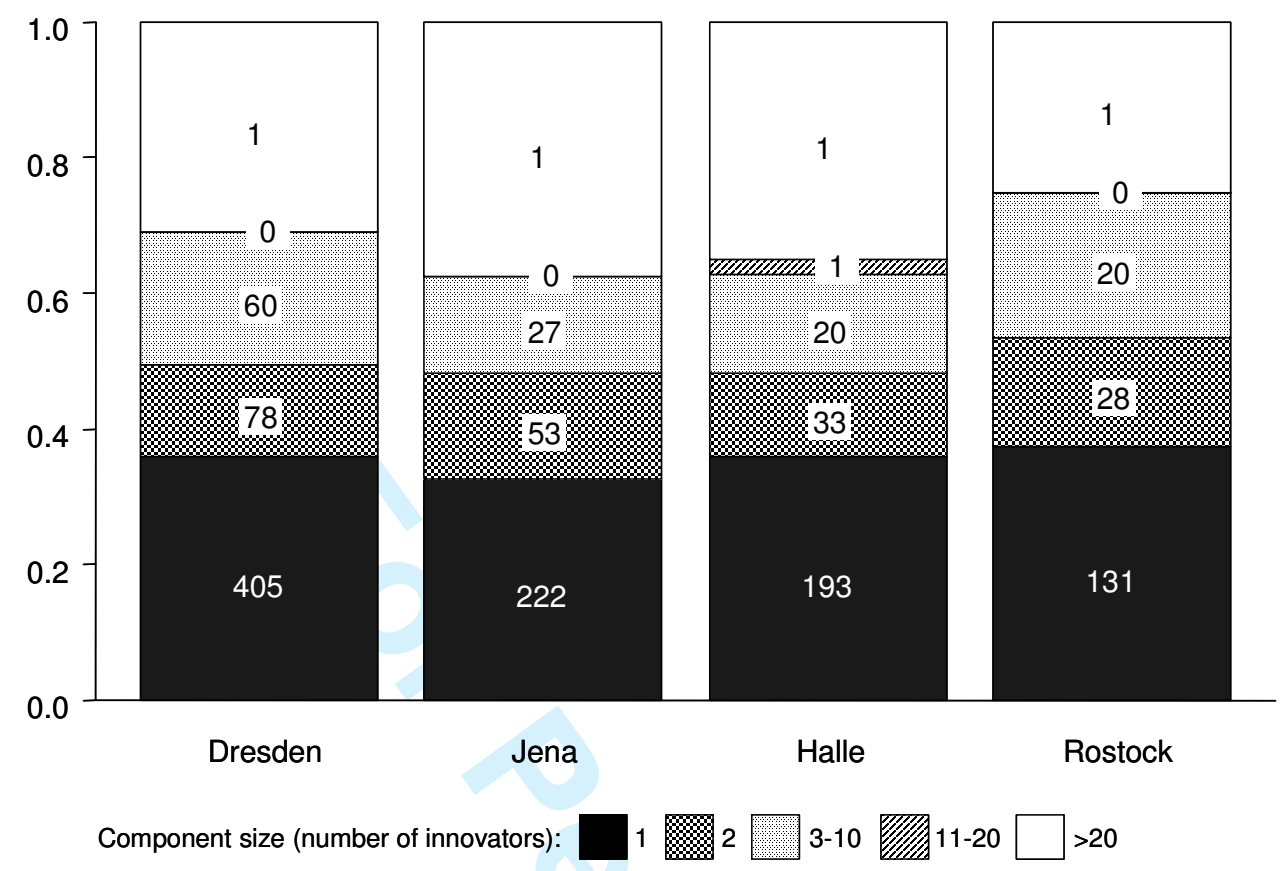

Note: Numbers on bar segments indicate the number of components of respective size. Example: In Dresden we find 405 components of size one (isolated innovators) - this is equivalent to a share of $35.8 \%$ in all innovators of the region (see table 3). Only one component consists of more than 20 innovators. This is the main component of the network (as shown in figure 1) collecting $30.9 \%$ of all innovators of Dresden.

Figure 5: Component distribution of the network of personal relationships 1995-2001 

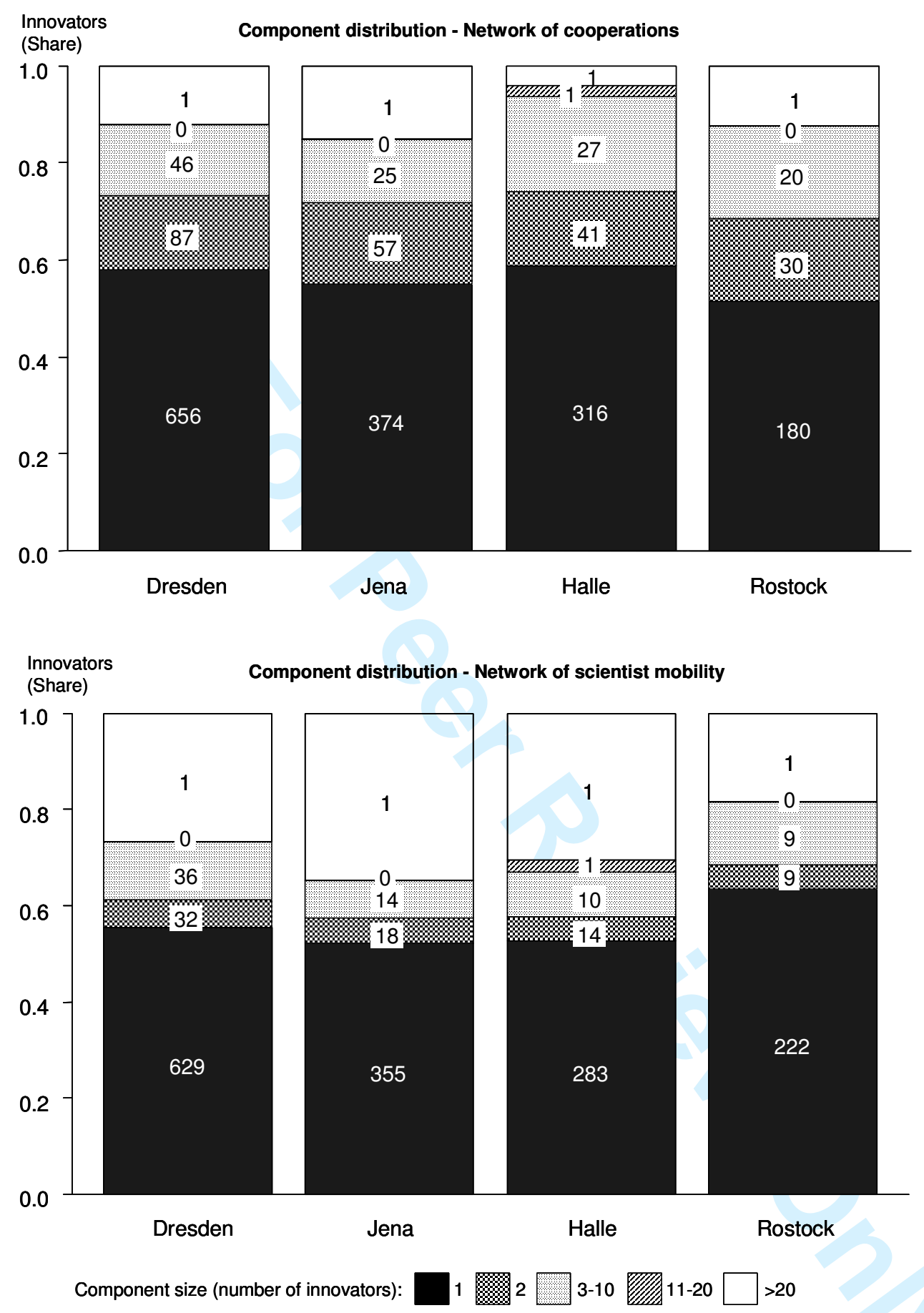

Note: Numbers on bar segments indicate the number of components of respective size.

Figure 6: Component distribution of the networks of cooperation and scientist mobility 1995-2001 

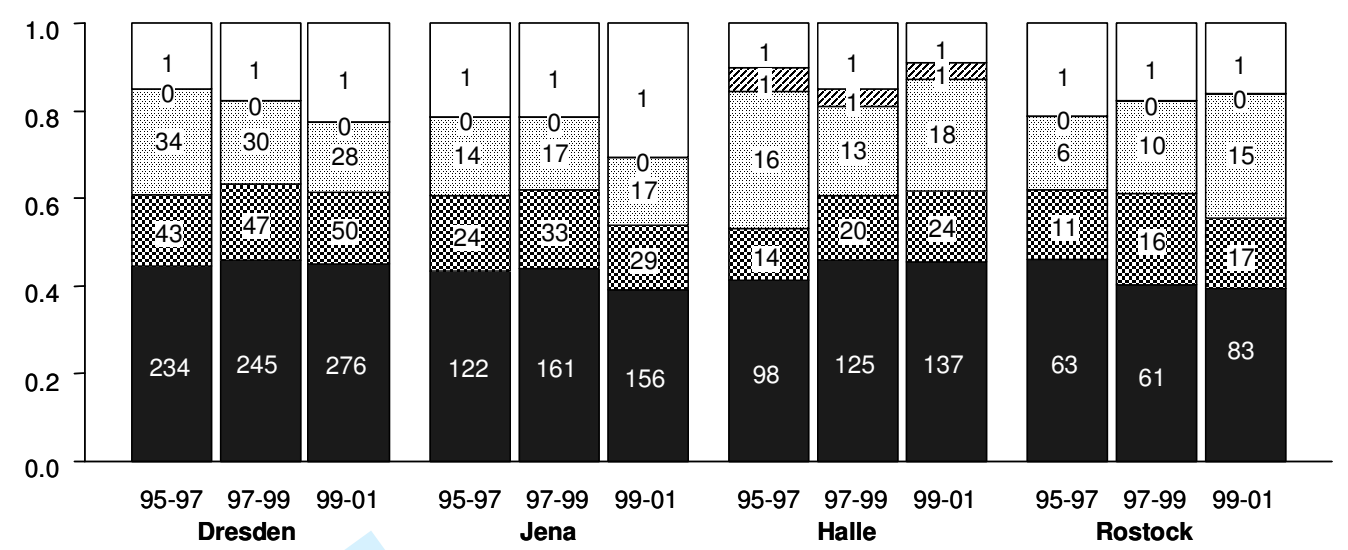

Component size (number of innovators):

95-97 97-99 99-01

95-97 97-99 99-01 Halle

Rostock

Note: Numbers on bar segments indicate the number of components of respective size.

Figure 7: Development of the component distribution of the network of personal relationships 